Published in final edited form as:

Rheumatol Int. 2017 October ; 37(10): 1611-1618. doi:10.1007/s00296-017-3782-6.

\title{
Hydroxychloroquine dosing in immune-mediated diseases: Implications for patient safety
}

\author{
Milena A. Gianfrancesco, PhD MPH, \\ Division of Rheumatology, University of California, San Francisco; 513 Parnassus Avenue, San \\ Francisco, CA 94143 \\ Gabriela Schmajuk, MD MS, \\ Division of Rheumatology, University of California, San Francisco; Veterans Affairs Medical \\ Center, San Francisco
}

Sarah Haserodt, MD,

Department of Medicine, California Pacific Medical Center

Laura Trupin, MPH,

Division of Rheumatology, University of California, San Francisco

Zara Izadi, PharmD,

Department of Epidemiology and Biostatistics, University of California, San Francisco

Kashif Jafri, MD,

Division of Rheumatology, University of California, San Francisco

Stephen Shiboski, PhD,

Department of Epidemiology and Biostatistics, University of California, San Francisco

Marina Sirota, PhD,

Institute for Computational Health Sciences, University of California, San Francisco; Marina

R. Adams Dudley, MD MBA, and

Center for Healthcare Value, Philip R. Lee Institute for Health Policy Studies, University of

California, San Francisco

Jinoos Yazdany, MD MPH

Division of Rheumatology, University of California, San Francisco

\begin{abstract}
Objective-Evidence suggests that hydroxychloroquine (HCQ) retinal toxicity is more common than previously thought. Adhering to careful weight-based dosing can significantly reduce the risk
\end{abstract}

*Corresponding author and requests for reprints: Milena Gianfrancesco PhD MPH; Division of Rheumatology, University of California, San Francisco; 513 Parnassus Avenue, San Francisco, CA 94143; Milena.Gianfrancesco@ucsf.edu.

CONFLICT OF INTEREST

All authors report no conflicts of interest regarding this manuscript.

ETHICAL APPROVAL

All procedures performed in studies involving human participants were in accordance with the ethical standards of the institutional and/or national research committee and with the 1964 Helsinki declaration and its later amendments or comparable ethical standards.

For this type of study formal consent is not required. 
of this adverse event and is recommended in recentguidelines. We used electronic health record data from a large health system to examine HCQ dosing over a five-year period and to identify risk factors associated with higher dosage of HCQ.

Methods-We constructed a longitudinal, retrospective cohort of patients with HCQ prescriptions (1,681 patients with 3,490 prescribing events) between 2012-2016. We measured HCQ dosing patterns relative to guidelines $(<6.5 \mathrm{mg} / \mathrm{kg}$ and $<5.0 \mathrm{mg} / \mathrm{kg}$ ) over time and used longitudinal multivariate mixed effects logistic regression to identify sociodemographic, clinical and health system factors associated with receiving higher than recommended doses of HCQ.

Results-The proportion of patients receiving doses above $6.5 \mathrm{mg} / \mathrm{kg}$ decreased from $12 \%$ in 2012 to $7 \%$ by 2016 . Similarly, the proportion of patients with doses above $5.0 \mathrm{mg} / \mathrm{kg}$ fell from $38 \%$ in 2012 to $30 \%$ in 2016 . Low body weight ( $<68 \mathrm{~kg}$ ) was strongly associated with receiving doses of HCQ above $6.5 \mathrm{mg} / \mathrm{kg}$ across all time points, even after adjusting for other factors (ORs ranging from 13.2-21.0).

Conclusion-Although the proportion of patients receiving higher than recommended HCQ doses has declined over a period of five years, a substantial number of individuals remain at increased risk for toxicity. Given the widespread use of HCQ in immune-mediated diseases, our study suggests that interventions aimed to ensure appropriate dosing are warranted to improve patient safety.

\section{Keywords}

Hydroxychloroquine; guidelines; patient safety; risk factors

\section{INTRODUCTION}

Hydroxychloroquine (HCQ) has been a mainstay of treatment for immune-mediated diseases like systemic lupus erythematous (SLE) and rheumatoid arthritis (RA) since the 1950s. The drug generally has an excellent safety profile and is often continued for many years or even indefinitely in patients to control disease. However, the drug-induced ocular side effects of HCQ have gained increasing attention. Previously considered rare (estimated $0.5-2 \%$ of long term users) [1-3], a 2014 landmark study estimated that retinal toxicity may be as high as $7.5 \%$ in prevalent users [4]. Importantly, this study demonstrated that the prevalence of retinal toxicity is less than $2 \%$ in the first 10 years of HCQ use for individuals prescribed doses $4.0-5.0 \mathrm{mg} / \mathrm{kg}$, compared to $10 \%$ for individuals exceeding this threshold. After 20 years, the risk increased to $40 \%$ for doses $>5.0 \mathrm{mg} / \mathrm{kg}$, and may rise up to $50 \%$ for those with concurrent kidney disease. Based on this data [4], the American Academy of Ophthalmology (AAO) issued weight-based recommendations for HCQ dosing in recent guidelines [5].

Retinal toxicity from HCQ can be severe and is generally irreversible. However, regular screening can identify retinal changes at an early stage before significant visual loss has occurred. Stopping HCQ when early toxicity is discovered usually halts progress enough to avoid damage to the fovea, and therefore prevents clinically noticeable visual loss. Despite the effectiveness of screening, prevention of toxicity is important to preserve the ability to use HCQ over the long-term. Although clinicians are aware of the need for HCQ retinal 
screening, studies to date suggest that many patients are receiving higher than recommended doses of the drug. For example, several studies have found that the prevalence of daily dosing above the 2011 AAO recommendation $(6.5 \mathrm{mg} / \mathrm{kg}$ ) ranges from $13-74 \%$ [1, 6-9], with estimates based on actual weight [1], ideal weight [6, 8-9], or the lesser of the two [7].

The goal of our study was to perform a comprehensive evaluation of HCQ dosing in routine clinical practice and to identify specific patient populations that are at higher risk for receiving doses associated with retinal toxicity. By looking at HCQ dosing episodes over time, we also sought to assess whether practice is adapting to incorporate the 2011 and updated AAO guidelines. To our knowledge, this is the first study to examine prescribing episodes of HCQ dosing longitudinally and to characterize populations at higher risk for patient safety events.

\section{MATERIALS AND METHODS}

\section{Study Population}

Data derive from the EHR of a large university health system with over 750,000 outpatient visits per year. EHR data available included demographics, diagnosis grouper codes, medications, clinical encounter notes, and scanned documents. We included all patients who received a prescription for HCQ in our health system between June 1, 2012 (the date on which the EHR was implemented) and September 1, 2016. We categorized the dates of the prescriptions by calendar year to measure dosage above guidelines longitudinally: 2012 (06/01/2012-12/31/2012), 2013, 2014, 2015, and 2016 (01/01/2016-09/01/2016). Because patients could have more than 1 prescription for HCQ within a year, we used the HCQ dose at the last prescription within each time-period to determine HCQ dosage for a given individual.

A total of 3,637 prescribing events were extracted over the five time-periods. Twenty prescribing events were excluded as they represented short-term HCQ use for malaria prophylaxis. After additionally removing duplicate prescribing events, a total of 3,490 prescriptions remained for 1,681 unique individuals.

Because some patients had a varying schedule of HCQ pills per day, daily dose of HCQ (mg) was calculated as the total prescribed amount over a week period (as derived from prescription order "description" [e.g. hydroxychloroquine, chloroquine, or Plaquenil], "sig" [e.g. "Take one tablet twice daily on even numbered days and once daily on odd numbered days"], and "discrete dose" [e.g. 200] fields from the EHR) divided by seven days. Since the biological half-life of HCQ is relatively long (more than 40 days) [10], precise dosing schemes did not seem of clinical importance for this study and instead the average daily dosage over a week was used. Chart reviews were conducted if description fields were blank ( $\mathrm{n}=96$ ); five prescriptions were missing dosage that could not be obtained through chart review. Daily dose (mg) was divided by each patient's recorded weight $(\mathrm{kg})$ in the EHR during the year of prescription. Weight data were available for 2,901 prescribing events. For missing values, recorded weight within 2 years prior to prescription was used if available in the EHR ( $\mathrm{n}=166$ ), leaving approximately $12 \%$ of prescribing events with missing weight values $(n=423)$. 
The outcome was defined as dosage above the 2011 AAO guidelines ( $\leq 6.5 \mathrm{mg} / \mathrm{kg}$ vs. $>6.5$ $\mathrm{mg} / \mathrm{kg}$ daily), or dosage above the updated AAO guidelines ( $\leq 5.0 \mathrm{mg} / \mathrm{kg}$ vs. $>5.0 \mathrm{mg} / \mathrm{kg}$ daily) for each time-period. Both outcomes were based on actual body weight in order to directly compare estimates and interpret findings. A previous study also found that actual weight was a better predictor of retinal toxicity than ideal body weight, and actual weight accounted for risk evenly over a wide range of body types [4]. The outcome variable was available for a total of 3,067 prescribing events across the five time-periods.

\section{Covariates}

Covariates in our study included sex, age, race, weight, insurance type, provider specialty, number of face-to-face rheumatology visits per year, and a number of clinical status variables. Primary diagnosis requiring HCQ was extracted from the index HCQ prescription or from the corresponding clinical notes and categorized into three groups for statistical analyses, allowing for a sufficient sample size in each level of the variable: systemic autoimmune disease (systemic lupus erythematosus, rheumatoid arthritis, dermatomyositis, unspecified connective tissue disease, sarcoidosis, scleroderma, Sjogren's disease), primary dermatologic disease (lichen planus/plano-pilaris, alopecia, discoid lupus), or other. Ordering clinic was defined by the specialty of the ordering supervising physician who prescribed the HCQ. Comorbidity was measured using a modified Charlson score calculated according to the Deyo protocol [11]. Liver and renal disease were characterized based on subscores of the Charlson index: mild liver disease (cirrhosis without portal hypertension, chronic hepatitis); moderate or severe liver disease (cirrhosis with portal hypertension + /variceal bleeding); and moderate or severe renal disease (creatinine $>3 \mathrm{mg} / \mathrm{dl}$ ), dialysis, transplantation, uremic syndrome). In a sub-analysis, estimated glomerular filtration rate (eGFR) was used in place of a diagnosis code for renal disease in a subanalysis. eGFR was derived from creatinine values according to the Chronic Kidney Disease Epidemiology Collaboration equation, which is based on age, gender, and race (African American vs. nonAfrican American) [12], for the year in which HCQ was prescribed. History of macular eye disease was determined from ICD code (retinal detachments and defects; chorioretinal scar; vitreomacular traction; and/or other retinal disorder).

\section{Statistical analysis}

The proportion of individuals dosed above AAO guidelines $(>6.5 \mathrm{mg} / \mathrm{kg}$ and $>5.0 \mathrm{mg} / \mathrm{kg}$ daily) was calculated for each year (2012-2016). Longitudinal multivariate mixed effects logistic regression models were used to identify sociodemographic, clinical and health system factors associated with dosage above guidelines across all years. Age, Charlson score, renal disease, eGFR, number of rheumatology face-to-face visits per year, and macular eye disease were not associated with dosing according to either criteria (univariate analyses, p>0.05) and thus were not included in the final models. All variables in the final model were confirmed to be non-collinear. We assumed that data were missing not at random, and modeled missing variables to be imputed (weight, dosage above or below 6.5 $\mathrm{mg} / \mathrm{kg}$, and dosage above or below $5.0 \mathrm{mg} / \mathrm{kg} ; \mathrm{n}=423,12 \%$ ) based on age, sex, race/ ethnicity, insurance, and Charlson score using chained equations (Stata, 'mi impute chained'). We imputed dosage on a number of variables given that prescription patterns may vary due to other factors beyond weight. We specified 5 imputations and a burn-in period of 
10. To predict future estimates of dosing practices, ARIMA time series models were utilized specifying the outcome as the percentage of individuals dosed above AAO guidelines at each time point. All analyses were conducted using Stata v.13.1 or R v.3.3.1. The study was approved by the Committee on Human Research at the University of California, San Francisco (Study Number: 15-17561).

\section{RESULTS}

Demographic and disease characteristics of individuals included in the study are demonstrated in Table 1. More than $80 \%$ of patients were female and $42 \%$ white. Mean age was 44.48 (+/-19.39) years. Rheumatologists ordered over half of HCQ prescriptions, and $69 \%$ were prescribed for a systemic autoimmune disease. On average, individuals were observed across $2.08(+/-1.26)$ time-periods.

The proportion of patients receiving higher than recommended doses of HCQ decreased during 2012-2016 according to both AAO guidelines (Figure 1). Approximately 12\% of patients were dosed above the $6.5 \mathrm{mg} / \mathrm{kg}$ recommendation in 2012, but this proportion dropped to $7 \%$ by 2016 . Similarly, $38 \%$ of patients were dosed above the $5.0 \mathrm{mg} / \mathrm{kg}$ recommendation in 2012, and 30\% in 2016.

Factors associated with HCQ dosing above AAO recommendations are demonstrated in Table 2. Dosing above $6.5 \mathrm{mg} / \mathrm{kg}$ was significantly associated with female sex $(\mathrm{OR}=5.46$, 95\% CI 1.89, 15.72), African American race compared to whites ( $\mathrm{OR}=0.14,95 \%$ CI 0.03 , 0.58 ), mild liver disease ( $\mathrm{OR}=0.17,95 \% \mathrm{CI} 0.04,0.73)$, Medicaid insurance compared to private insurance $(\mathrm{OR}=0.26,95 \% \mathrm{CI} 0.09,0.77)$, and other indication compared to systemic autoimmune disease (OR=3.20, 95\% CI 1.03, 9.91) after controlling for the stated variables as well as ordering clinic, indication and year. After additionally controlling for weight, only Medicare and Medicaid insurance status were significantly associated with dosage status. Medicare insurance was associated with higher odds of being dosed above guidelines $(\mathrm{p}=0.004)$, while Medicaid insurance was associated with a decreased odds $(\mathrm{p}=0.005)$. As expected, increasing weight $(\mathrm{kg})$ was significantly associated with decreased odds of being dosed above guidelines $(\mathrm{p}<0.001)$. Each year was also associated with decreased odds of being dosed above guidelines ( $\mathrm{p}$-value for trend $=0.002$ ), with the largest decrease occurring in year 2016 as compared to $2012(\mathrm{OR}=0.27,95 \%$ CI $0.12,0.63 ; \mathrm{p}=0.002)$.

Dosage above $5.0 \mathrm{mg} / \mathrm{kg}$ was inversely associated with African American race $(\mathrm{OR}=0.30$, $95 \%$ CI $0.11,0.79)$ and Hispanic ethnicity $(\mathrm{OR}=0.28,95 \%$ CI $0.12,0.64)$ compared to whites, and Medicaid insurance $(\mathrm{OR}=0.23,95 \% \mathrm{CI} 0.11,0.50)$ and uninsured status ( $\mathrm{OR}=0.12,95 \% \mathrm{CI} 0.02,0.76)$ compared to those with private insurance. Patients being prescribed HCQ through the dermatology clinic had over a six-fold risk of receiving higher than recommended doses compared to patients prescribed HCQ through the rheumatology clinic (OR=6.55, 95\% CI 2.64, 16.24). All associations beside African American race persisted after adjusting for weight; in addition, Asian individuals were significantly less likely to be dosed above guidelines ( $\mathrm{OR}=0.39,95 \%$ CI $0.17,0.87$ ). Similar to findings for $6.5 \mathrm{mg} / \mathrm{kg}$, year and weight were inversely associated with HCQ dose above $5.0 \mathrm{mg} / \mathrm{kg}$ $(\mathrm{p}<0.001)$. 
Stratification by weight demonstrated that $14-22 \%$ of patients exceeded the $6.5 \mathrm{mg} / \mathrm{kg}$ guideline if they weighed $<68 \mathrm{~kg}$ (or 150 pounds, the median weight in our study sample) compared to $0-1 \%$ of patients $\geq 68 \mathrm{~kg}$ over the entire study period. In a multivariate analysis, individuals weighing less than $68 \mathrm{~kg}$ were at highest risk for receiving HCQ doses above $6.5 \mathrm{mg} / \mathrm{kg}$ across all time points after adjusting for covariates (ORs ranging from $13.2-21.0 ; \mathrm{p}<0.01)$. On average, those receiving higher than recommended doses were prescribed $0.7-1.2 \mathrm{mg} / \mathrm{kg}$ over $6.5 \mathrm{mg} / \mathrm{kg}$. Approximately $39-47 \%$ of patients exceeded the $5.0 \mathrm{mg} / \mathrm{kg}$ guideline if they weighed $<68 \mathrm{~kg}$ compared to $21-26 \%$ of people $\geq 68 \mathrm{~kg}$ over the study period. Similar to findings for $6.5 \mathrm{mg} / \mathrm{kg}$, individuals weighing less than $68 \mathrm{~kg}$ were at highest risk for receiving HCQ doses above $5.0 \mathrm{mg} / \mathrm{kg}$ across all time points after adjusting for covariates (ORs ranging from 1.9-2.8; $\mathrm{p}<0.01$ ). On average, those prescribed higher than recommended doses received $0.8-1.1 \mathrm{mg} / \mathrm{kg}$ over the $5.0 \mathrm{mg} / \mathrm{kg}$ criteria.

Sensitivity analyses demonstrated that age, Charlson score, insurance (Medicaid, uninsured), and ordering clinic (dermatology, other) were significantly associated with missing weight (12\%), which could potentially influence results, since weight is required for dose calculations. Therefore, we conducted multiple imputation to assign weight, as well as dosage above or below $6.5 \mathrm{mg} / \mathrm{kg}$ and $5.0 \mathrm{mg} / \mathrm{kg}$, for missing values (final $\mathrm{n}=3,490$ prescribing events). Imputed data demonstrated results consistent with our main findings, indicating that missing data were not likely to influence conclusions.

Time series modeling projected that in 2017, approximately $9 \%$ of individuals will be dosed above the $6.5 \mathrm{mg} / \mathrm{kg}$ recommendations (95\% CI 5.49, 12.51), and 32.6\% of individuals will be dosed above the $5.0 \mathrm{mg} / \mathrm{kg}$ recommendations (95\% CI 26.71, 38.49), suggesting that if passive diffusion of knowledge continues, it may require several years for a significant decrease in the proportion of individuals on high doses of HCQ.

\section{DISCUSSION}

We sought to examine the uptake of AAO patient safety guidelines on clinical practice within a large university health center. The International Classification for Patient Safety framework highlights the importance of detection and characterization of mitigating factors as key elements in the prevention and reduction of risk [13]. Our analyses showed that over the five year period, the percentage of individuals with HCQ dosing inconsistent with both guidelines decreased; however, in 2016, approximately 1 in 14 patients were still prescribed $\mathrm{HCQ}>6.5 \mathrm{mg} / \mathrm{kg}$, and 1 in $3>5.0 \mathrm{mg} / \mathrm{kg}$. On average, the patients who were prescribed HCQ doses in excess of the guidelines received HCQ doses of $1 \mathrm{mg} / \mathrm{kg}$ above the recommended dose, which over time may be clinically meaningful and could contribute to an increased number of adverse events [4].

Studies of practice patterns in a variety of health care settings have reported that the proportion of patients receiving daily doses of HCQ above $6.5 \mathrm{mg} / \mathrm{kg}$ is consistently high [14], ranging from 13-74\% [1, 6-9]. While our estimates were lower than those published, there are important differences to note. Previous reports included a small number of participants with at least five years of HCQ use [6], provided estimates among individuals also seen by ophthalmologist [9] or undergoing HCQ screening in an ophthalmology 
practice [7], or calculated dosing according to ideal rather than actual body weight [6, 8-9]. Our 2011 prevalence estimate for dosage above $6.5 \mathrm{mg} / \mathrm{kg}(12 \%)$ is consistent with findings from a large, national longitudinal study ( $\mathrm{n} 4,000)$ of RA and SLE patients published in 2010 that based estimates on actual body weight (13\%) [1].

Prior literature has identified barriers to uptake of new clinical guidelines by clinicians, including lack of awareness, lack of familiarity, lack of outcome expectancy, lack of agreement with the evidence, lack of self-efficacy, external barriers, and inertia of previous practice $[15,16]$. In cases where patients did not have weight recorded, receiving doses above recommended guidelines may be due to clinicians' lack of awareness or familiarity with the AAO criteria, or inertia of previous practice, when prescription of HCQ did not incorporate an individual's weight. Lack of agreement with guidelines is also a potential factor influencing clinician uptake, as the extent to which the $5.0 \mathrm{mg} / \mathrm{kg}$ criteria should be upheld is currently debated [17]. For example, clinicians may intentionally prescribe doses above recommendations to better manage a patient's disease, and lowering HCQ dose in certain individuals has the potential to increase symptoms and disease activity $[18,19]$. There is also concern that lowering dosage may cause patients to fall out of therapeutic range of HCQ, as various factors have been associated with blood concentration of HCQ, such as renal insufficiency, high estimated creatinine clearance, and disease activity [20, 21]. Since the newer recommendation is based on one retrospective case-control study of patients within Kaiser Permanente [4], additional, prospective studies are needed to assess whether the $5.0 \mathrm{mg} / \mathrm{kg}$ threshold significantly reduces risk of retinal toxicity in other populations. Comprehensive and consistent retinal screening remains critical to monitoring the risk of adverse events in patients.

Characterizing factors associated with inappropriate dosing may assist in identifying targets for quality improvement. We found that ordering clinic, specifically dermatology, was significantly associated with dosage above $5.0 \mathrm{mg} / \mathrm{kg}$, but not $6.5 \mathrm{mg} / \mathrm{kg}$. This line of evidence may suggest an unfamiliarity with or rejection of the newer guidelines. While missing weight was associated with dermatology as the ordering clinic, a significant association between dermatology and HCQ dose above $5.0 \mathrm{mg} / \mathrm{kg}$ remained after imputation of missing weight values, indicating that our main results were not likely to be biased by missing data. Given that no difference in weight was found between any of the ordering clinics (before and after imputation), dosage above $5.0 \mathrm{mg} / \mathrm{kg}$ within dermatology may also be due to a failure to routinely weigh patients and therefore an inability to tailor an individual's dosage appropriately. Clinical decision support that incorporates weight measurement and suggests weight-based dosing may encourage clinician adherence to guidelines and facilitate patient safety improvement [22].

Our findings also indicated that lower weight is a risk factor for dosing above the recommended levels. We found that individuals who weighed less than $68 \mathrm{~kg}$ (or 150 pounds) were significantly more likely to be dosed above guidelines compared to individuals weighing more than $68 \mathrm{~kg}$. Further, as previously noted [15], HCQ pill size (200 mg) is not optimized for safe dosing, as it is typically prescribed as 1 or 2 pills, without attention to whether this dosage meets AAO guidelines according to a patient's weight. Our results 
further encourage lobbying to manufacturers to create additional options for pill doses in order to ensure appropriate dosing.

Strengths of our study include a longitudinal, comprehensive evaluation of HCQ dosing in a large university health system while accounting for a number of covariates over a period of five years. We also identified certain patient groups more likely to receive doses above current guidelines, thus at higher risk for patient safety events. Limitations of the study include the university setting of patient information, which may reflect a more severe patient population and may not be generalizable to other populations. We assessed dosage using EHR records of the last prescription within the year, which may not reflect the actual dosage taken by patients as advised by clinicians through face-to-face patient instructions or other means. We were not able to assess whether higher HCQ doses was associated with retinal toxicity and/or other adverse effects. Additionally, we were not able examine underlying disease activity or detailed clinical decision making around potentially deliberate dosing of HCQ above guidelines. Lastly, we were not able to evaluate the influence of the time duration of the drug prescription for this study. Because a majority of patients were prevalent users of hydroxychloroquine and because our electronic health record includes only five years of data, we are unable to calculate a drug initiation date for a majority of patients at this time.

Adverse effects of medications, such as retinopathy, can be experienced by patients taking HCQ and may be more common than previously reported. Efforts to routinely screen patients can assist in identifying early signs of retinal toxicity, but appropriate HCQ dosing strategies are critical to ensure that patients can safely use this important medication. Our longitudinal data suggest that uptake of AAO guidelines is encouraging, with substantial improvements in the number of individuals dosed above both $6.5 \mathrm{mg} / \mathrm{kg}$ and $5.0 \mathrm{mg} / \mathrm{kg}$ criteria. Our findings point to specific patient-level factors, such as lower body weight, and health system factors, such as clinical visits in which weight is not measured, that should be targets for quality improvement. Clinical decision support may assist in increasing clinician adherence to current guidelines, especially where there exists a lack of awareness, lack of familiarity, or inertia of previous practice. These approaches have the potential to improve patient safety on a large scale by reducing the risk of HCQ-associated adverse outcomes.

\section{Acknowledgments}

We thank Chris Tonner and Dana Ludwig for their technical assistance with this project.

\section{FUNDING}

This work is supported by AHRQ R01 HS024412 (JY) and NIAMS K23 AR063770 (GS). Dr. Gianfrancesco has received funding from the Rheumatology Research Foundation. Dr. Yazdany is supported by the Robert L. Kroc Endowed Chair in Rheumatic and Connective Tissue Disorders. Drs. Yazdany and Schmajuk are also supported by the Russell/Engleman Medical Research Center for Arthritis. Dr. Sirota is funded in part by the March of Dimes Prematurity Research Center. Dr. Jafri is supported by an NIH T32 grant 5T32AR007304-38. The content is solely the responsibility of the authors and does not necessarily represent the official views of the Agency for Healthcare Research and Quality, National Institute of Arthritis and Musculoskeletal and Skin Diseases, or National Institutes of Health. 


\section{References}

1. Wolfe F, Marmor MF. Rates and predictors of hydroxychloroquine retinal toxicity in patients with rheumatoid arthritis and systemic lupus erythematosus. Arthritis Care Res (Hoboken). 2010; 62:775-784. [PubMed: 20535788]

2. Levy GD, Munz SJ, Paschal J, Cohen HB, Pince KJ, Peterson T. Incidence of hydroxychloroquine retinopathy in 1,207 patients in a large multicenter outpatient practice. Arthritis Rheum. 1997; 40:1482-1486. [PubMed: 9259429]

3. Mavrikakis I, Sfikakis PP, Mavrikakis E, Rougas K, Nikolaou A, Kostopoulos C, et al. The incidence of irreversible retinal toxicity in patients treated with hydroxychloroquine: a reappraisal. Ophthalmology. 2003; 110:1321-1326. [PubMed: 12867385]

4. Melles RB, Marmor MF. The risk of toxic retinopathy in patients on long-term hydroxychloroquine therapy. JAMA Ophthalmol. 2014; 132:1453-1460. [PubMed: 25275721]

5. Marmor MF, Kellner U, Lai TY, Melles RB, Mieler WF. American Academy of Ophthalmology. Recommendations on Screening for Chloroquine and Hydroxychloroquine Retinopathy (2016 Revision). Ophthalmology. 2016; 123:1386-1394. [PubMed: 26992838]

6. Cukras C, Huynh N, Vitale S, Wong WT, Ferris FL, Sieving PA. Subjective and objective screening tests for hydroxychloroquine toxicity. Ophthalmology. 2015; 122:356-366. [PubMed: 25444344]

7. Browning DJ. Impact of the revised american academy of ophthalmology guidelines regarding hydroxychloroquine screening on actual practice. Am J Ophthalmol. 2013; 155:418-428. [PubMed: 23218706]

8. Lee MG, Kim SJ, Ham DI, Kang SW, Kee C, Lee J, et al. Macular retinal ganglion cell-inner plexiform layer thickness in patients on hydroxychloroquine therapy. Invest Ophthalmol Vis Sci. 2014; 56:396-402. [PubMed: 25425304]

9. Braslow RA, Shiloach M, Macsai MS. Adherence to hydroxychloroquine dosing guidelines by rheumatologists: an electronic medical record-based study in an integrated health care system. Ophthalmology. 2017; [Epub ahead of print]. doi: 10.1016/j.ophtha.2016.12.021

10. Tett SE, Cutler DJ, Day RO, Brown KF. Bioavailability of hydroxychloroquine tablets in healthy volunteers. Br J Clin Pharmacol. 1989; 27:771-779. [PubMed: 2757893]

11. Deyo RA, Cherkin DC, Ciol MA. Adapting a clinical comorbidity index for use with ICD-9-CM administrative databases. J Clin Epidemiol. 1992; 45:613-619. [PubMed: 1607900]

12. Levey AS, Stevens LA, Schmid CH, Zhang YL, Castro AF, Feldman HI, et al. A new equation to estimate glomerular filtration rate. Ann Intern Med. 2009; 150:604-612. [PubMed: 19414839]

13. Sherman H, Castro G, Fletcher M, Hatlie M, Hibbert P, Jakob R, et al. Towards an International Classification for Patient Safety: the conceptual framework. Int J Qual Health Care. 2009; 21:2-8. [PubMed: 19147595]

14. Browning DJ. The Prevalence of Hydroxychloroquine Retinopathy and Toxic Dosing, and the Role of the Ophthalmologist in Reducing Both. Am J Ophthalmol. 2016; 166:9-11.

15. Cabana MD, Rand CS, Powe NR, Wu AW, Wilson MH, Abboud PA, et al. Why don't physicians follow clinical practice guidelines? A framework for improvement. JAMA. 1999; 282:1458-1465. [PubMed: 10535437]

16. Hall SF, Irish JC, Gregg RW, Groome PA, Rohland S. Adherence to and uptake of clinical practice guidelines: lessons learned from a clinical practice guideline on chemotherapy concomitant with radiotherapy in head-and-neck cancer. Curr Oncol. 2015; 22:e61-68. [PubMed: 25908922]

17. Schwartzman, S. My Take on New Ocular Screening Guidelines for Plaquenil. RheumNow. 2016. http://rheumnow.com/blog/my-take-new-ocular-screening-guidelinesplaquenil\#.WA1IG9L24n4.email Accessed 25 Nov 2016.

18. The Canadian Hydroxychloroquine Study Group. A randomized study of the effect of withdrawing hydroxychloroquine sulfate in systemic lupus erythematosus. N Engl J Med. 1991; 324:150-154. [PubMed: 1984192]

19. Tsakonas E, Joseph L, Esdaile JM, Choquette D, Senecal JL, Cividino A, et al. A long-term study of hydroxychloroquine withdrawal on exacerbations in systemic lupus erythematosus. Lupus. 1998; 7:80-85. [PubMed: 9541091] 
20. Jallouli M, Galicier L, Zahr N, Aumaotre O, Frances C, Le Guern V, et al. Determinants of hydroxychloroquine blood concentration variations in systemic lupus erythematosus. Arthritis Rheumatol. 2015; 67:2176-2184. [PubMed: 25989906]

21. Lee JY, Lee J, Kwok SK, Ju JH, Park KS, Park SH. Factors related to blood hydroxychloroquine concentration in patients with systemic lupus erythematosus. Arthritis Care Res (Hoboken). 2016; [Epub ahead of print]. doi: 10.1002/acr.22962

22. Institute of Medicine (US) Committee on Standards for Developing Trustworthy Clinical Practice Guidelines. Chapter 6: Promoting Adoption of Clinical Practice Guidelines. In: Graham, R.Mancher, M., Miller Wolman, D., editors. Clinical Practice Guidelines We Can Trust. National Academies Press; Washington: 2011. https://www.ncbi.nlm.nih.gov/books/NBK209543/ 


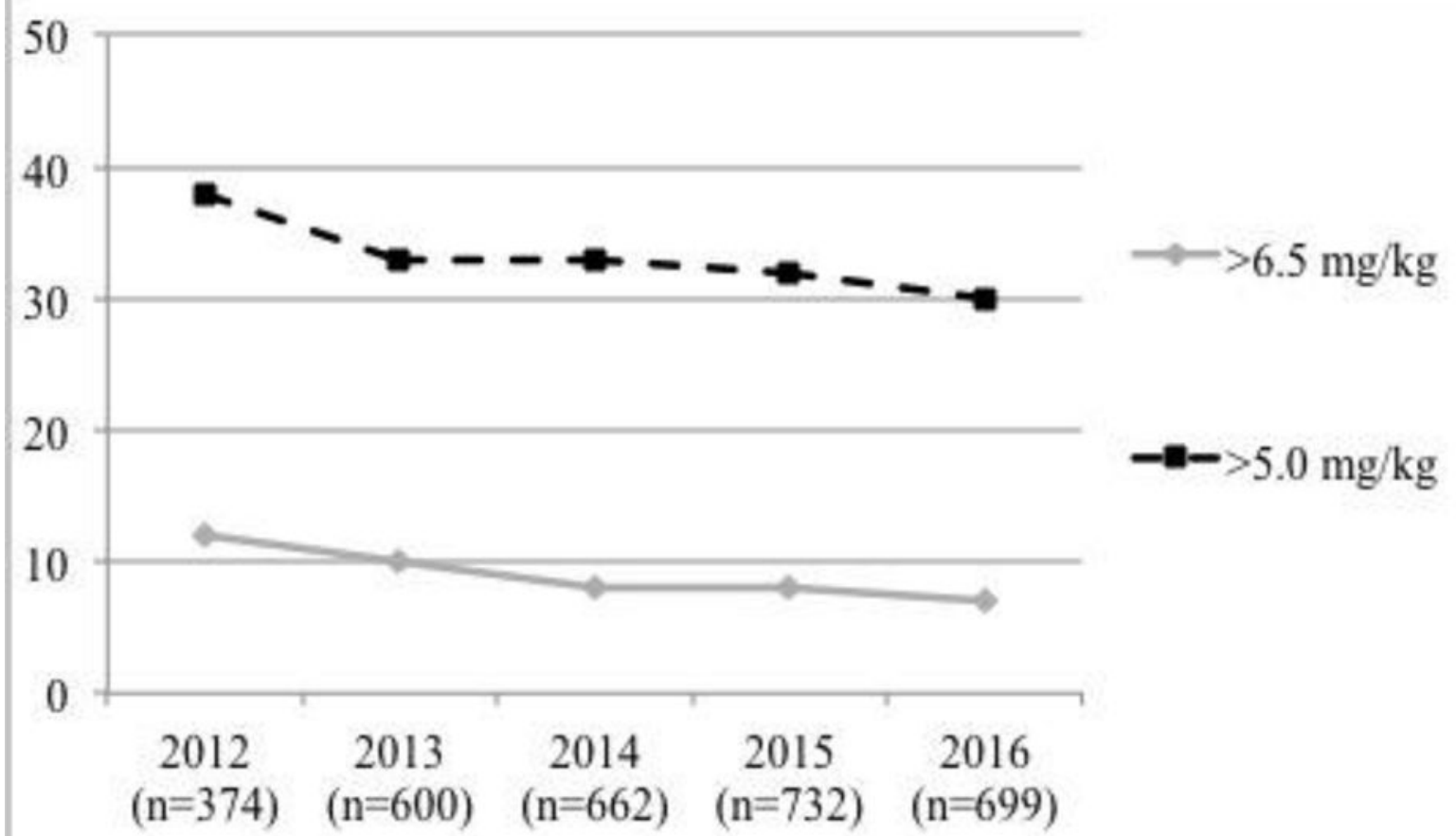

Figure 1.

Proportion of patients who exceeded AAO hydroxychloroquine dosing guidelines, by year (multivariate adjusted $\mathrm{p}$-value for trend $=0.002$ and $<0.001$, for $>6.5$ and $>5.0 \mathrm{mg} / \mathrm{kg}$, respectively). 


\section{Table 1}

Demographic and disease characteristics of individuals prescribed hydroxychloroquine at first prescribing event $(n=1,681)$

\begin{tabular}{|c|c|}
\hline Characteristic & $\mathbf{N}(\%)$ or mean $(+/-\mathrm{SD})$ \\
\hline Number of time periods with prescribing event & $2.07+/-1.26$ \\
\hline Female & $1,375(82 \%)$ \\
\hline \multicolumn{2}{|l|}{ Age } \\
\hline$<18$ & $162(10 \%)$ \\
\hline $18-50$ & $805(48 \%)$ \\
\hline $51-75$ & $642(38 \%)$ \\
\hline$>75$ & $74(4 \%)$ \\
\hline \multicolumn{2}{|l|}{ Race } \\
\hline White & $711(42 \%)$ \\
\hline African American & $167(10 \%)$ \\
\hline Hispanic & $264(16 \%)$ \\
\hline Asian & $247(15 \%)$ \\
\hline Other/multiple & $292(17 \%)$ \\
\hline \multicolumn{2}{|l|}{ Insurance Type } \\
\hline Private & $853(51 \%)$ \\
\hline Medicare & $452(27 \%)$ \\
\hline Medicaid & $316(19 \%)$ \\
\hline Uninsured & $62(4 \%)$ \\
\hline \multicolumn{2}{|l|}{ HCQ ordering provider specialty (clinic) } \\
\hline Rheumatology & $972(58 \%)$ \\
\hline Dermatology & $420(25 \%)$ \\
\hline General Internal Medicine/ Primary Care & $85(5 \%)$ \\
\hline Other & $206(12 \%)$ \\
\hline Number of face-to-face rheumatology visits per year & $3.81(2.36)$ \\
\hline \multicolumn{2}{|l|}{ Indication for HCQ } \\
\hline Systemic Autoimmune Disease & $1,154(69 \%)$ \\
\hline Primary Dermatologic Disease & $297(18 \%)$ \\
\hline Other & $277(14 \%)$ \\
\hline Charlson score & $2.27+/-2.63$ \\
\hline Renal disease ${ }^{\#}$ & $255(15 \%)$ \\
\hline \multicolumn{2}{|l|}{ Glomerular filtration rate $\left(\mathrm{mL} / \mathrm{min} / 1.73 \mathrm{~m}^{2}\right)$} \\
\hline$>60$ & $1,745(91 \%)$ \\
\hline$\leq 60$ & $167(9 \%)$ \\
\hline Mild liver disease ${ }^{\#}$ & $137(8 \%)$ \\
\hline Moderate/Severe liver disease ${ }^{\#}$ & $21(1 \%)$ \\
\hline \multicolumn{2}{|l|}{ Weight (kg) } \\
\hline Females & $69.17+/-20.59$ \\
\hline
\end{tabular}




\begin{tabular}{|c|c|}
\hline Characteristic & $\mathbf{N}(\%)$ or mean $(+/-\mathrm{SD})$ \\
\hline Males & $82.46+/-22.9$ \\
\hline \multicolumn{2}{|l|}{ Macular Eye Disease ${ }^{*}$} \\
\hline Retinal detachments and defects & $3(<1 \%)$ \\
\hline Chorioretinal scar & $4(<1 \%)$ \\
\hline Vitreomacular traction & $1(<1 \%)$ \\
\hline Other retinal disorder & $31(2 \%)$ \\
\hline \multicolumn{2}{|l|}{$\hat{n}=1,092$} \\
\hline \multicolumn{2}{|c|}{$\begin{array}{l}\text { \# Defined using Charlson Comorbidity Index: mild liver disease (cirrhosis without portal hypertension, chronic hepatitis); moderate or severe liver } \\
\text { disease (cirrhosis with portal hypertension +/- variceal bleeding); and moderate or severe renal disease (creatinine }>3 \mathrm{mg} / \mathrm{dl} \text { ), dialysis, } \\
\text { transplantation, uremic syndrome). }\end{array}$} \\
\hline
\end{tabular}

Percentages may not equal 100 due to rounding. 


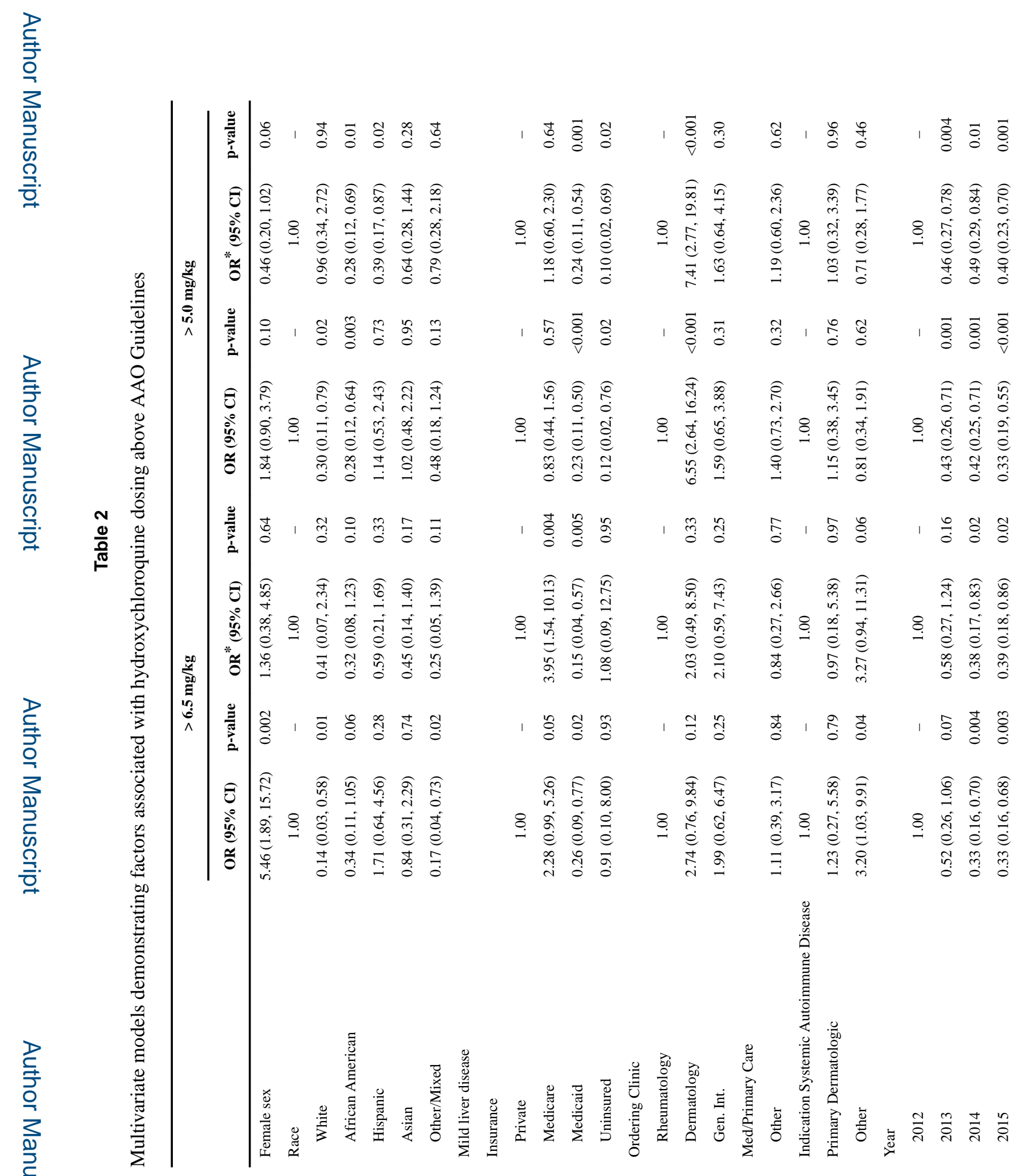

Rheumatol Int. Author manuscript; available in PMC 2018 October 01. 


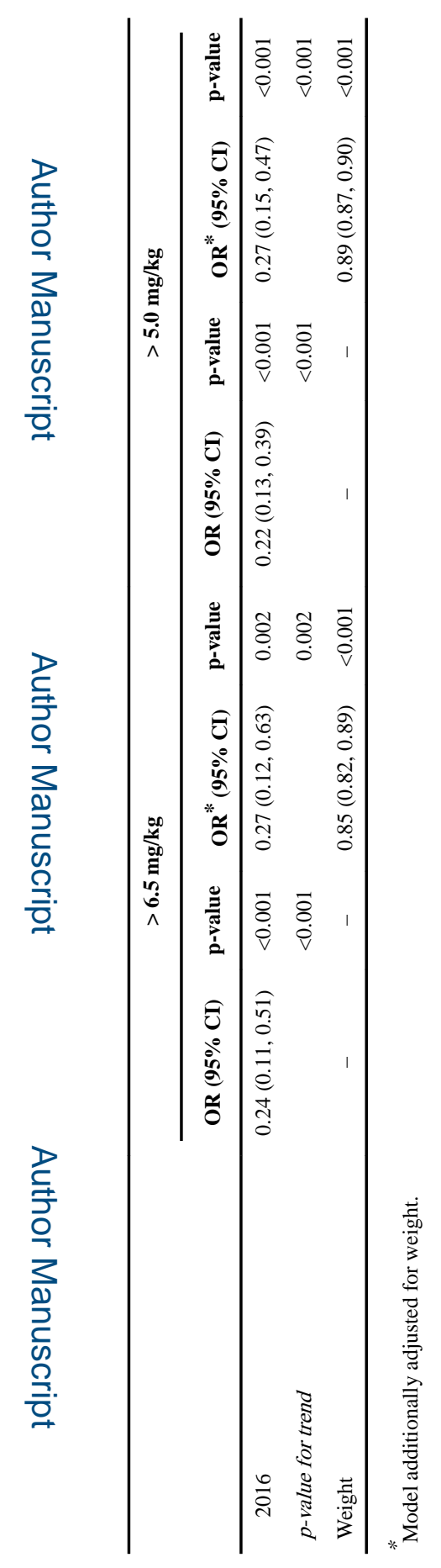

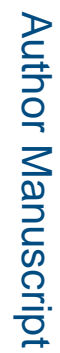

